\title{
BEEF MARKETS - STATE, TRENDS AND POLICY
}

\author{
T. Turlakova*, S. Genov
}

\author{
Department of "Agricultural Economics”, University of Economics - Varna, Bulgaria
}

\begin{abstract}
Main goal of paper is to analyze beef markets and maintain factors which define supply, demand and prices on international, national and local markets (the example is Bulgarian beef market). The study trying to discover some relations between different factors of the beef market and to assess their impact to pricing at that food supply chain. Most of results are presented at chronological order by mean, absolute and relive values. For determining influence between them is applied factor, correlation and regression analysis. The objectives of paper - beef cattle and supply chain were selected because this sector was developing at Bulgaria in recent years. Bulgarian Ministry of agriculture and food reported meat cows are doubled from 2011 to 2016 and recovered beef meat at carcass weight growing with $8 \%$ on year base. Whereas Bulgaria is traditional importer of beef (around $1 / 3$ of consummation is covered by imported meat) although ecological resources are very appropriate for developing meat cattle. Those conditions putting meat cattle sector at perspective at Bulgarian livestock but effectiveness at producing and distribution depends of markets factors and policy decisions, which are subject of the study.
\end{abstract}

Key words: cattle pricing, bovine meat, live weight, carcass prices

\section{INTRODUCTION}

The article analyzes the beef and veal market by exploring the factors influencing demand, supply and prices at international, regional and national levels. The study is concentrated on the trends in the European Union and Bulgaria in last 10 years - from 2007 to 2016. It's trying to discover, describe and evaluate some interconnections and dependencies on the beef market and their impact on pricing in that meat supply chain.

\section{MATERIALS AND METHODS}

For the assessment of the state and trends in the beef and veal sector are used respectively four main groups of indicators:

1) Bovine cattle and beef and veal production

2) Trade and consumption of meat of bovine animals (bovine meat)

3) Prices of meat cattle and produced meat from them

4) Agricultural policy

In the article is used mainly information from secondary sources, which are aggregated in the appropriate form for analysis purposes. The

\footnotetext{
"Correspondence to: Teodorina Turlakova, Department of "Agricultural economics", University of economics - Varna, Bulgaria, 9002 Varna, 77 Knyaz, Boris I Blvd, +359882165160, tturlakova@ue-varna.bg
}

sources of data are official publications of organizations and institutions related to agribusiness such as Food and agricultural organization of Union of united nations (FAO), United states department of agriculture (USDA), Organization for Economic Cooperation and Development (OECD), Directorate-General for Agriculture and Rural Development of European Commission, Eurostat, Ministry of agriculture, food and forestry at Bulgaria, National statistical institute (NSI) and etc. Most of the indicators are presented in chronological order by mean, absolute and relative values. Factor, correlation, and regression analysis were applied to determine the influence between them.

\section{RESULTS AND DISCUSSION}

World beef production depends on the number of bovine animals, whether they are from specialized meat species or not. The FAOSTAT data show that world-wide the number of cattle does not stop growing until 2014 and they reach 1475 million animals (3.3\% more than in 2007) (1). The largest number of cattle between 2007 and 2013 are breeding in Brazil (14.2\%), India (13\%), China (7.9\%), USA (6.2\%) and Argentina (3\%). World meat production by cattle is also growing with average year rate of $0.5 \%$ for the 
same period (2007-2014) and reached 64681 thousand tons in 2014 (2).

The ranking of the leading countries in the production of beef (harvested in slaughterhouses) does not coincide with the number of breeding animals (Figure 1). At first place is US, which produced $18.4 \%$ of world beef meat, followed by Brazil with $14.3 \%$, China with $9.5 \%$ and Argentina with $4.4 \%$. Therefore, the link between the number of bovine animals and the quantities of produced meat is not directly proportional.

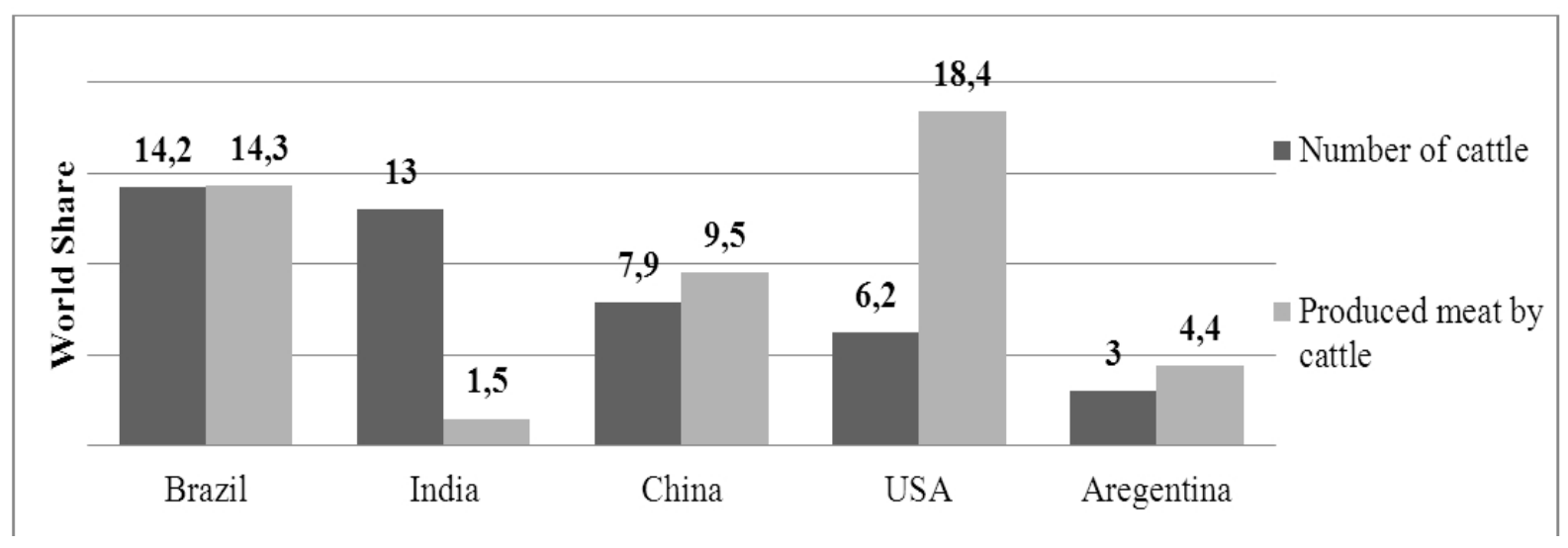

Figure 1. Top 5 world producers of cattle and beef Source: FAOSTAT

USDA reports that cattle in the world are declining in 2015 by $2.8 \%$ compared to 2014 , but it's expected in 2017 the number of them to return at 2014 levels. The same trend is also formed for the worldwide production of bovine meat. In 2015 the decrease was $1.84 \%$ compared to 2014, but in 2017 is expected to regain its volumes and even surpass levels in 2014 (3).

By the FAO annual forecast reports is expected meat production to grow steadily from 2016 onwards, mainly due to higher productivity (4). The 2016-2025 report indicates that beef production will grow by $20 \%$ over the baseline period 2013-2015 in developing countries such as Argentina, Brazil, India and China, which together will producing $2 / 3$ of the world's beef meat. In developed countries, growth is expected to be $7 \%$, mainly from North America and Russia. The projections for Europe are to reduce beef production, despite the targeted support of the sector by Common Agricultural Policy.

The increase in the number of cattle and produced meat increases the internationally supply. Exports of beef accounted 8.29\% of total production in 2007 and $8.42 \%$ in 2013 , showing a slight increase in traded volumes (2). Expectations for greater production will further boost international supply, which will increase competition between the leaders of beef international trading. Therefore, this may reduce the prices of beef which marketed in the world.
The consumption of beef per capita for the period 2013-2015 in the world is average 6.49 $\mathrm{kg}$ per year (5). It's highest in Brazil and North America - around $25 \mathrm{~kg} /$ year and lowest in the Asian region - 2.9kg/year. In the EU, according to OECD data, average beef consumption is $10.61 \mathrm{~kg}$ per capita. The OECD forecasts predicts that world consumption per capita will increase insignificantly over the next 10 years. The largest increase is expected in Asia, where it's possibility to reach $3.36 \mathrm{~kg}$ in 2025 . The USDA also predicts an increase in consumption at East Asian, especially in China, which will increase exports and competition for this market (4).

The global supply and demand ratio determines the average international beef prices. Over the past ten years there were increasing in beef prices in nominal and real terms (Figure 2). The highest level is in 2014 when the average price level in real terms reaches $\$ 5,118$ for carcass ton. These record levels are reached after several years of eradicating bovine herds in areas with the largest production, such as the United States. The data for world beef prices show that, despite the rise in producing, prices are also rising at even higher rates, indicating that trends over the period under review are a consumption increasing and a propensity to paying higher prices. In the next few years is expected a decline, which is expected to continue until 2020, and in 2017 the price is expected to fall below $\$ 4,000$ per ton. 
TURLAKOVA T., et al.

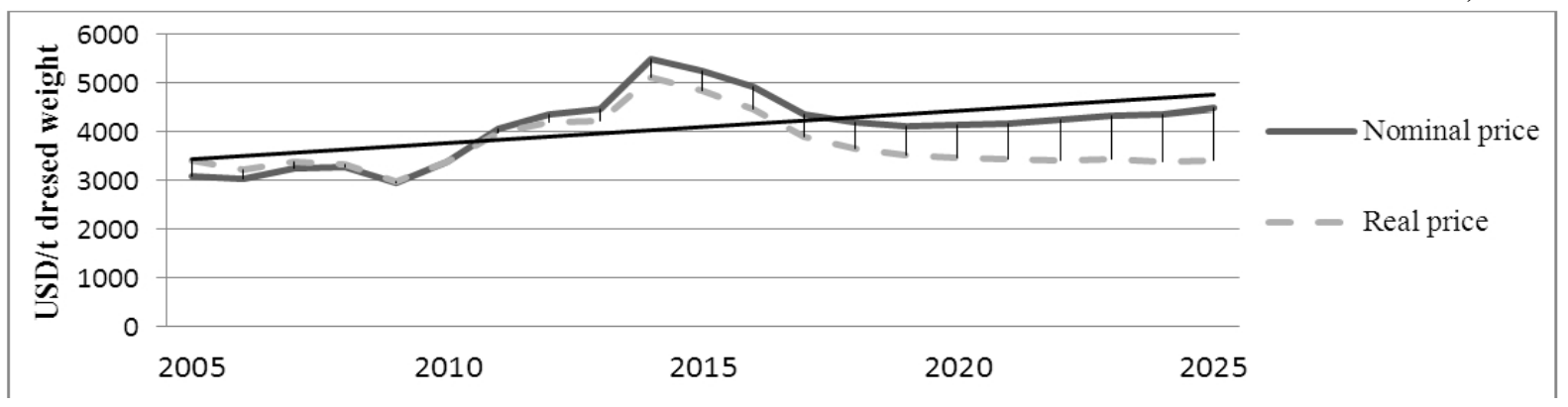

Figure 2. World beef meat prices Source: OECD

In the EU-28, according to EUROSTAT data, number of cattle were grown to 89,075 thousand heads in 2016, which is roughly also in 2015. For the period 2007-2016, animals minimum were counted in $2011-87054$ thousand heads. Like the global trends, since then the trend of increase and recovery of the initial levels from 2007 has been maintained (see Figure 3).

The largest number of cattle is in France $21.3 \%$, followed by Germany with $14 \%$ and Great Britain - 11\%. In geographic Europe, second place in number of cattle after France is Turkey with 14,2 millions.

About 570 thousand cattle are breeding in Bulgaria, which is an insignificant share of $0.64 \%$ at the EU-28. Before Bulgaria in the number of cattle ranks is Latvia by 695 thousand heads, and after is Greece with 554 thousand heads (6). The countries which are into this group have relatively weak influence on the European beef market. In such countries, meat cattle should aim to satisfying domestic consumption of fresh meat and possibly exporting higher-quality processed meat products.

Meat cows are $34.5 \%$ of the total number of cows in the EU at 2016 and their share rising steadily in recent years (in 2013 they were $33.7 \%$ ) (7). And in the case of meat cows, the leader is France with 4225 thousand heads, but on the second place is Spain with 1960 thousand heads, followed by Great Britain and Ireland.

The production of beef in the EU for 2016 is 7 784 thousandth tones, which compared to 2015 is by 200 thousand tons more, but compared to 2007 is 474 thousand tons less. At 2007 were harvested the largest quantities of beef in the EU - 8258 thousand tons but at 2009 was reported drastic decline, when the produced bovine meat was nearly 500000 tons less than the base year - 2007 (Figure 3).

Bovines processed by slaughterhouses at the beginning of the analyzed period (2007) are also the most - 29,149 thousand heads. In 2009 the decrease is almost 2,000 heads compared to 2007, and in 2016 their number (26 539 thousand) still can't reach the 2009 level (6).

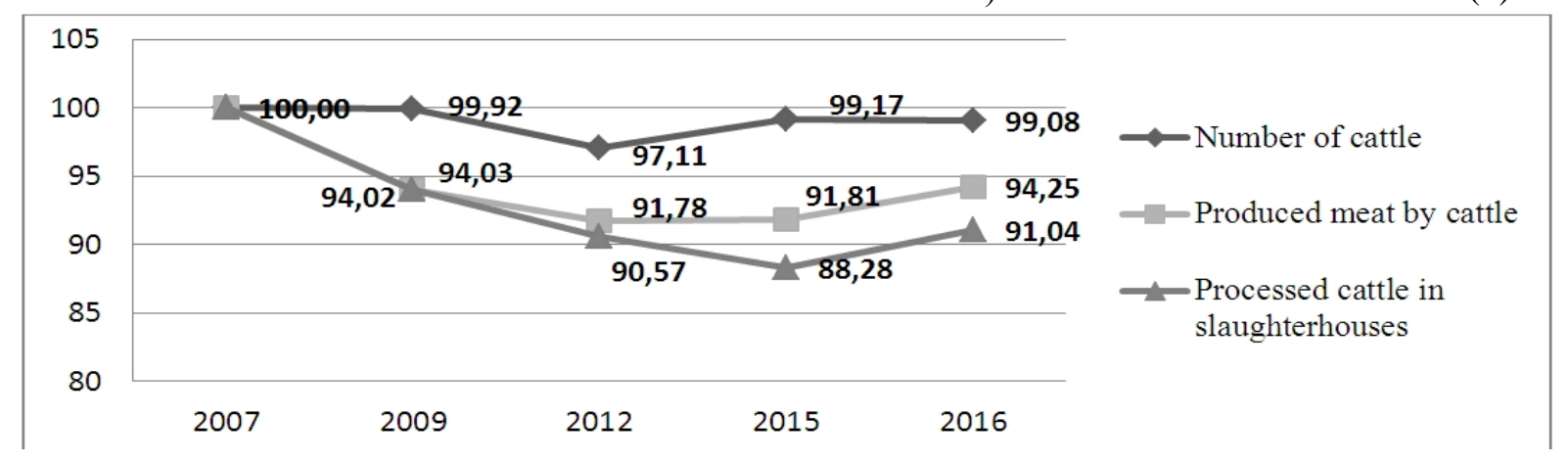

Figure 3. Trends at number of cattle and produced meat at EU-28 Source: EUROSTAT

It can't be drawn conclusive conclusion on the correlation between the number of bovines raised and the produced meat from them. The change in produced meat during 2007-2009 is greater than the change in the number of live cattle. In the next period 2009-2015 the trend is the opposite, the change in the number of animals is greater than the obtained meat. The impact of the processed animals on the quantities of obtained meat is also not proportional. For example, in 2012-2015 periods there was a drop in the number of 
processed animals of $2.29 \%$, and the produced meat is kept on its levels in 2012 (see Figure $3)$.

These tendencies are substantially influenced by the average meat production per animal, calculated as the ratio between the total meat yield and the number of processed animals. The lowest values of the average yield per animal for the whole analyzed period are in the base year $2007-283.32 \mathrm{~kg}$, and the highest in 2015 - $294.66 \mathrm{~kg}$. These average indicators include all categories of cattle which should be taken into account when interpreting results. For greater accuracy, cattle should be divided into age groups. 2015's results for calves and young cattle average for the EU-28 are $164.2 \mathrm{~kg}$.

The positive trend of the average meat productivity of cattle explains the inconsistencies in the proportions between the numbers of bred and processed cattle and the harvested meat. For example, in the period 2012-2015, there was a drop in the number of processed animals by $2.29 \%$ and at the same time an increase in the yield of one cattle by $4 \%$, indicating that reductions in the number of cattle were offset by the average animal yield.

The natural volumes of $E U$ beef trade show an upward trend in exports. For the last 5 years from 2012 to 2016 the exported quantities increased by 174 thousand tons, which equals to $35 \%$ upward. For 2016 the largest quantities are exported to Turkey, China, Lebanon and Israel (8). There are no substantial changes for imported quantities for the period 2012-2016, with an average import of 326 thousand tons in the EU per year. Importers with the largest share in the EU in 2016 are Brazil, Argentina, Uruguay and Australia (7).

The comparison of the imported quantities with the production volumes in the EU shows the insignificant participation of imported meat on the European beef market $-4.3 \%$ in 2016 .
TURLAKOVA T., et al.

The import / export ratio tends to make a positive change in the EU's external trade balance for quantities of beef, from $+49,000$ tons in 2012 it rises to $+148,000$ tons in 2016 . Therefore, trade with third countries at natural volumes in the last few years has been positively developing.

Values of exports follow growth rates as well as in kind, but with less relative growth. For 2016 the exported quantities are appreciate on 1,061 million EUR, which is $22.5 \%$ more than in 2012 (9). Imports also reported an increase in value - the largest one is in 2015 - over 2 billion euros. For the five years analyzed, the value of imports increased by $14.2 \%$, while in kind the growth was $8.4 \%$, which suggests that import prices are gradually rising. In contrast to the positive balance in natural quantities, the EU beef trade indicator is negative in value terms. The beef's external trade balance is steadily rising, from -881 million euros in 2012 to -934 million euros in 2016 (10).

Within the EU-28, the reported of the slaughterhouses average prices per 100 $\mathrm{kg} / \mathrm{carcass}$ weight (cwe) of all animal categories have tended to decline in recent years (Figure 4), but are still far higher than the reference price 222.40 euro under which is initiated a procedure of market intervention.

At the beginning of the analyzed period (second half of 2014), prices paid by slaughterhouses rose to 390 EUR, and in March 2015, there is a steady decline trend, the absolute minimum of which is in July 2016 357 euro. In the second half of 2016, average prices are rising, reaching $385 €$ at the end of the year, but then at the beginning of 2017 again a downward trend began. The average price for 2016 is 368euro, which is 16 euro lower compared to 2015. Compared with world trends, it has been showing relatively similar changes over these years.

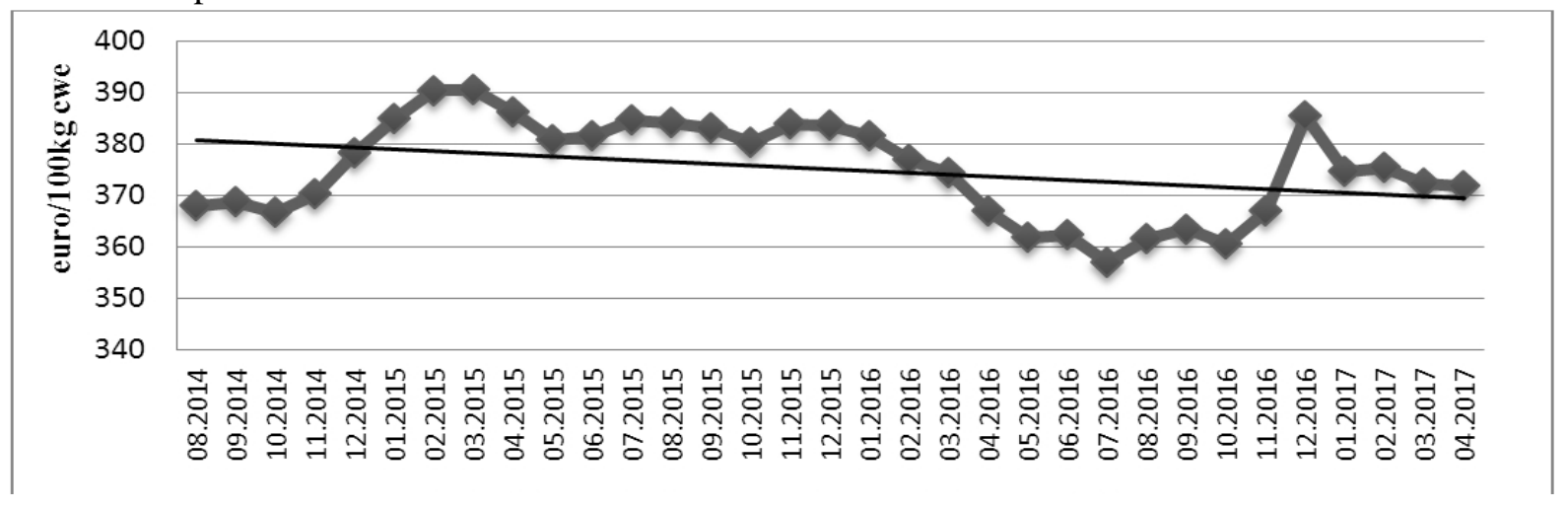

Figure 4. Monthly Average Carcass Prices at EU-28

Source: EC, Directorate-General for Agriculture and Rural Development

https://ec.europa.eu/agriculture/market-observatory/meat/latest-updates_en 
Purchase prices based on live weight for young cattle and heifers are traditionally closer, while cow prices are about $25 \%$ lower. The data from Figure 5 shows that despite the differences in the levels of the prices paid for the three categories the trends are same. At the begging of the 2007-2016 period, a constant increase in the price per $\mathrm{kg}$ of live weight is reported by 2013, after which prices are
TURLAKOVA T., et al. gradually declining. In the last reported year 2016 , the price is sharply decreasing and by 2015 younger cattle have dropped by $-9 \%$, heifers by $-10.8 \%$ and cows by $-9.8 \%$. In paying on a slaughter weight basis, the decline in the average price was $-4.24 \%$, indicating that the price variations in this model of payment were lower than those based on live weight.

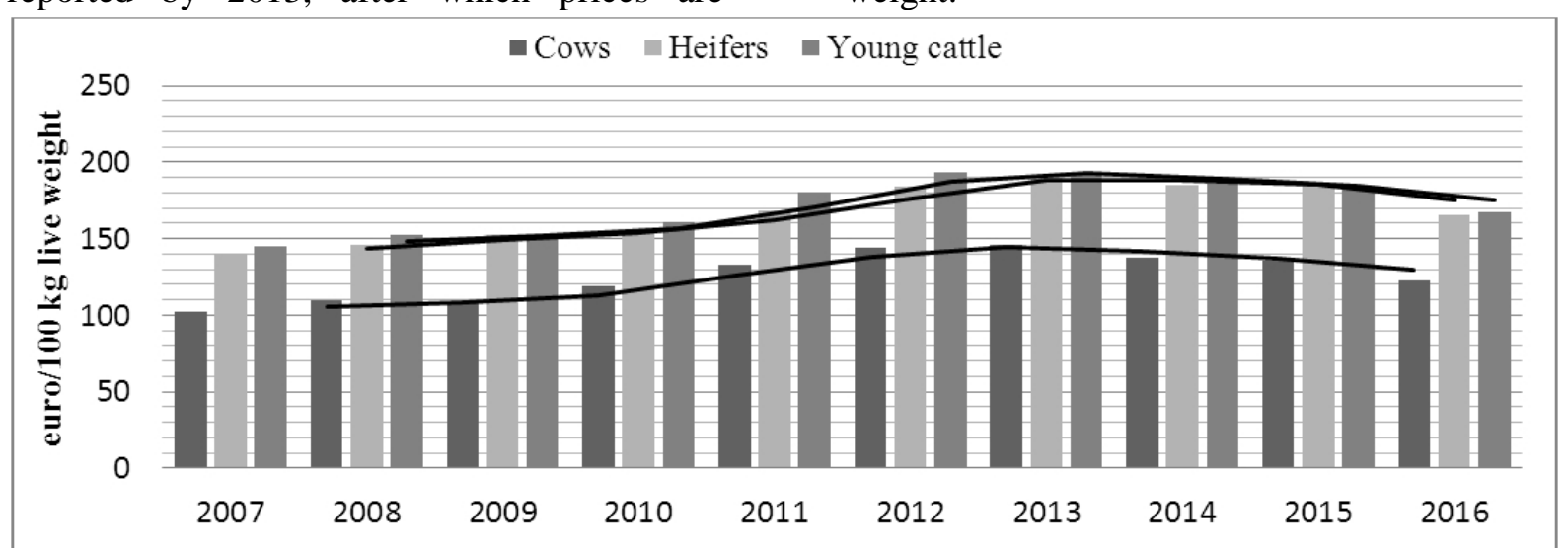

Figure 5. Prices on live weight base at EU Source: EUROSTAT

Other data for the payment for an animal prove by economic need for specialization in beef production. Male dairy calves are sold on average at 112.3 euro/pc in April 2017, while male calves of the meat type are 221.7 euro/pc (7). This almost double difference is due to several technological reasons, the most important of which is the yield and quality of the produced meat.

In Bulgaria there is a decrease trend in the number of cattle for the period 2007-2016, which is characteristic of the EU as a whole. By November 2016 they are nearly 580 thousand (11), 44 thousands less than 2007, which is a decrease of $7.34 \%$ versus only $1 \%$ across the EU. Between 2007 and 2012 there is clear declining trend and in 2012 cattle reach their minimum of 526 thousand. From 2013 is reported an increase in the number of cattle, which varies around 550,000 till 2016.

Meat cows form an increasing proportion of cows in Bulgaria (Figure 6), which shows a partial orientation of cattle sector to cattle breading for meat production. At the beginning of their counting in 2011 they are only $7 \%$, and by the end of 2016 they formed $24 \%$ of all cows. Despite the high rate of increase, the values are still less than from the Union as a whole, where the meat cows in 2016 are $34.5 \%$. Cows specializing for meat in Bulgaria have significant growth in relative terms to all cows as well as absolute values. For the period 2013-2016 in the EU-28 they have increased by $3.85 \%$ and in Bulgaria they are doubled.

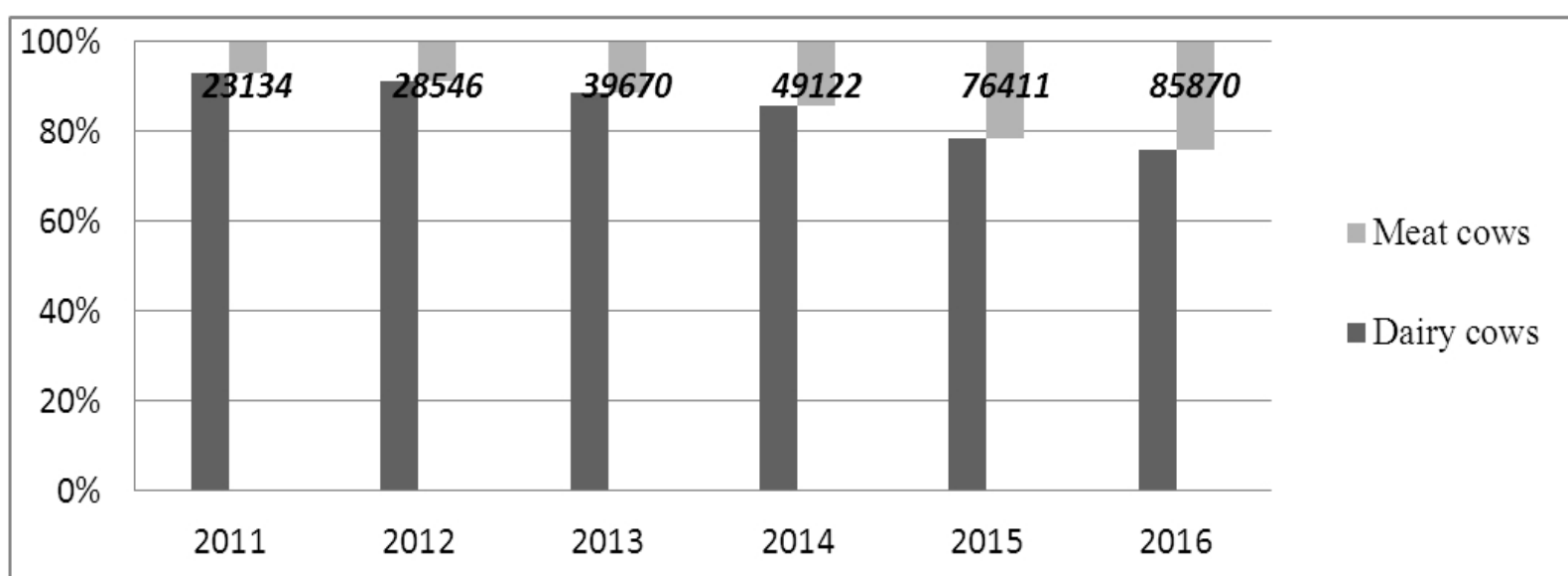

Figure 6. Share of meat and milk cows at Bulgaria

Source: Department "Agrostatistcs", Ministry of agriculture, food and forestry 
Changes in the structure of cattle breeding at Bulgaria can be seen as increasingly important. Expansion of cows for meat is important for satisfying the national market with bovine meat and for using the available natural resources in the country. Meat cattle breeding is an alternative for milk producers who can't meet the requirements but have production infrastructure, access to production resources and experience in cattle breeding.

Realized cattle, incl. transmitted to slaughterhouses, slaughtered on farms and sold to intermediaries, have steadily decreased over past 10 years in Bulgaria (Figure 7), similar to tendencies at EU. For the period 2007-2016
TURLAKOVA T., et al. they have abridged about $1 / 3$, which is unusual relative to there is no such significant decrease in the number of cattle in the country. For the last year - 2016 they are 137 thousand, which is by $8.1 \%$ less than 2015 (11).

Produced bovine meat in Bulgaria also tended to decrease during the analyzed period, and in 2015, was obtained 18548 tons carcass weight, which is $14.83 \%$ less than in 2007 (12), with an 7,8\% decline for EU. The change in the number of realized animals is in the same direction as the meat production, which indicates that the relationship between the indicators is straightforward.

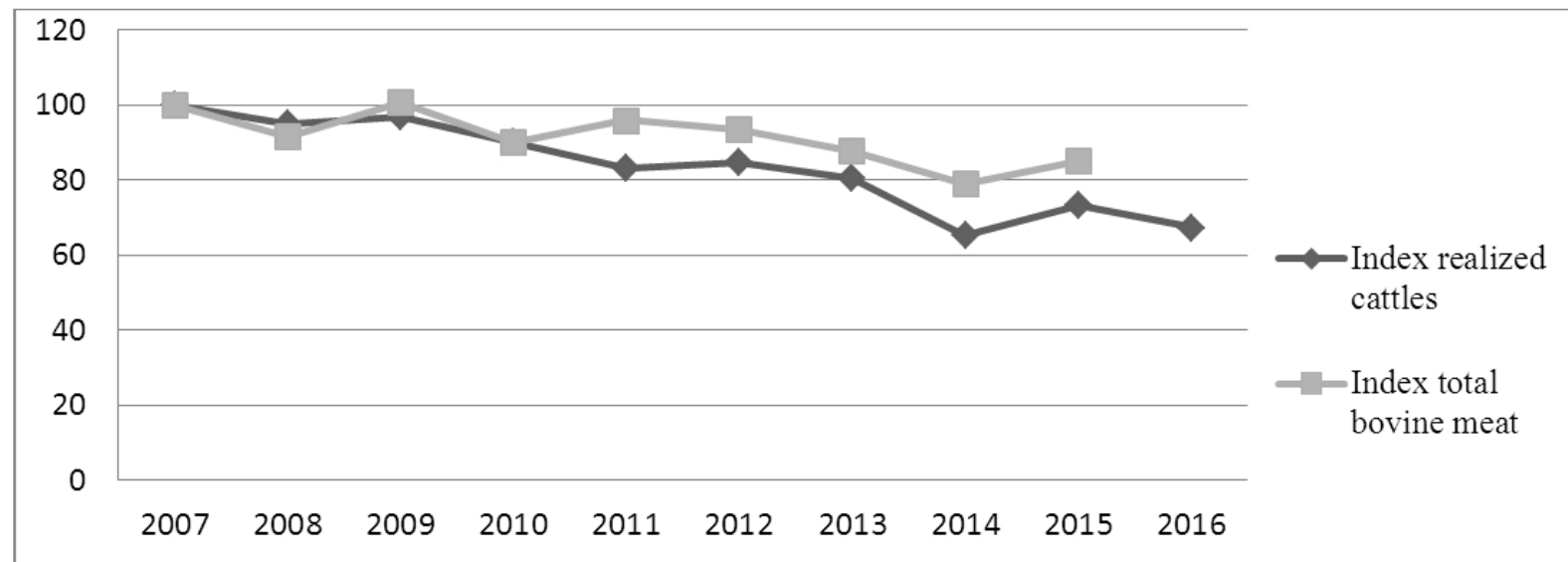

Figure 7. Realized cattle and produced bovine meat at Bulgaria Source: Ministry of agriculture, food and forestry, Department "Agrostatistcs"

During the analyzed period (2007-2015) the meat productivity of cattle in Bulgaria decreased from $150 \mathrm{~kg}$ per animal in 2007 to $135 \mathrm{~kg}$ in 2015 (Table 1). The decrease is entirely due to lower productivity in young cattle, while for the rest categories are kept at the same level. The results are also negative at the average randemann, which also falls by about $1 \%$ for both categories of animals. The main factors influencing these indicators are the species of animals and breeding technology. It can be concluded that realized animals are mostly dropped from the dairy cattle and at the moment of realizing, they are not optimally fattened.

If the result for Bulgaria compare with the average productivity in the EU $(294 \mathrm{~kg}$ in 2015), the indicator for all categories is so lower - $135 \mathrm{~kg}$. For adult animals it is $37 \%$ lower and for the young cattle by $35 \%$ in 2015 . These indicators have a significant effect on the purchase prices of bovines, and this should be taken into account when comparing prices in Bulgaria and the EU-28.

An obligatory element of the beef and veal market analysis is the ratio of harvested meat at registered slaughterhouses and at farms. The attitude of the meat obtained from cattle for 2015 in Bulgaria is $28.9 \%$ to $71.1 \%$, respectively. Although in recent years the tendency is to increase the share of slaughter yields (by about 5\% for the period 2010-2015), it is still too low. This has a significant impact on the organization of beef markets and is a key factor for pricing, quantitative and qualitative results in the sector.

The industrial production of bovine meat in Bulgaria is concentrated in 38 slaughterhouses, where in 2016 have been processed 32440 cattle. Compared to 2007 they are almost 2 thousand more and the meat produced in them has increased by nearly 800 tons. If analyzing the activity of slaughterhouses by months (Figure 8), is highlighted the seasonal yield of meat from bovine animals. In 2014, 2015 and 2016 is noticeable an increase in the gained carcass weight during the autumn-winter period (from September to December). Consequently, during this period, the market of meat cattle in Bulgaria has intensified. This may be due to the end of the grazing period and the needs of funds to buy feed for the winter period. 
TURLAKOVA T., et al.

Table 1. Production results at beef and veal producing in Bulgaria

\begin{tabular}{|l|r|r|r|r|r|}
\hline $\begin{array}{c}\text { Species and categories of } \\
\text { animals }\end{array}$ & $\begin{array}{c}\text { Slaughtered } \\
\text { animals } \\
\text { (thousandths) }\end{array}$ & $\begin{array}{c}\text { Live } \\
\text { weight } \\
\text { (tons) }\end{array}$ & $\begin{array}{c}\text { Carcass } \\
\text { weight } \\
\text { (tons) }\end{array}$ & \multicolumn{1}{c|}{$\begin{array}{c}\text { Average } \\
\text { productivity } \\
\text { (kg per animal) }\end{array}$} & $\begin{array}{c}\text { Randemann } \\
(\%)\end{array}$ \\
\hline \multicolumn{7}{|c|}{2015} \\
\hline Calves and young cattle & 99,1 & 21487,1 & 10524,7 & 106,20 & 49 \\
\hline Other cattle & 38,2 & 17403,5 & 8023,4 & 210,03 & 46,1 \\
\hline Cattle / total / & 137,3 & 38890,6 & 18548,1 & 135,09 & 47,7 \\
\hline \multicolumn{7}{|c|}{2012} \\
\hline Calves and young cattle & 89,6 & 19273,5 & 9592,2 & 107,06 & 49,77 \\
\hline Other cattle & 53,3 & 23563,3 & 10784,9 & 202,34 & 45,77 \\
\hline Cattle / total / & 142,9 & 42836,8 & 20377,1 & 142,60 & 47,57 \\
\hline \multicolumn{7}{|c|}{2009} \\
\hline Calves and young cattle & 99.6 & 24110.5 & 11888.3 & 119,36 & 49,31 \\
\hline Other cattle & 48.0 & 20815.0 & 10032.2 & 209,00 & 48,20 \\
\hline Cattle / total / & 147.6 & 44925.5 & 21920.5 & 148,51 & 48,79 \\
\hline \multicolumn{7}{|c|}{2007} \\
\hline Calves and young cattle & 91.8 & 21751.0 & 11083.8 & 120,74 & 50,96 \\
\hline Other cattle & 53.4 & 22795.5 & 10694.2 & 200,27 & 46,91 \\
\hline Cattle / total / & 145.2 & 44546.5 & 21778.0 & 149,99 & 48,89 \\
\hline
\end{tabular}

Source: Activity of slaughterhouses for red meat and meat production in Bulgaria 2007-2015, Ministry of agriculture, food and forestry, Department "Agrostatistcs"

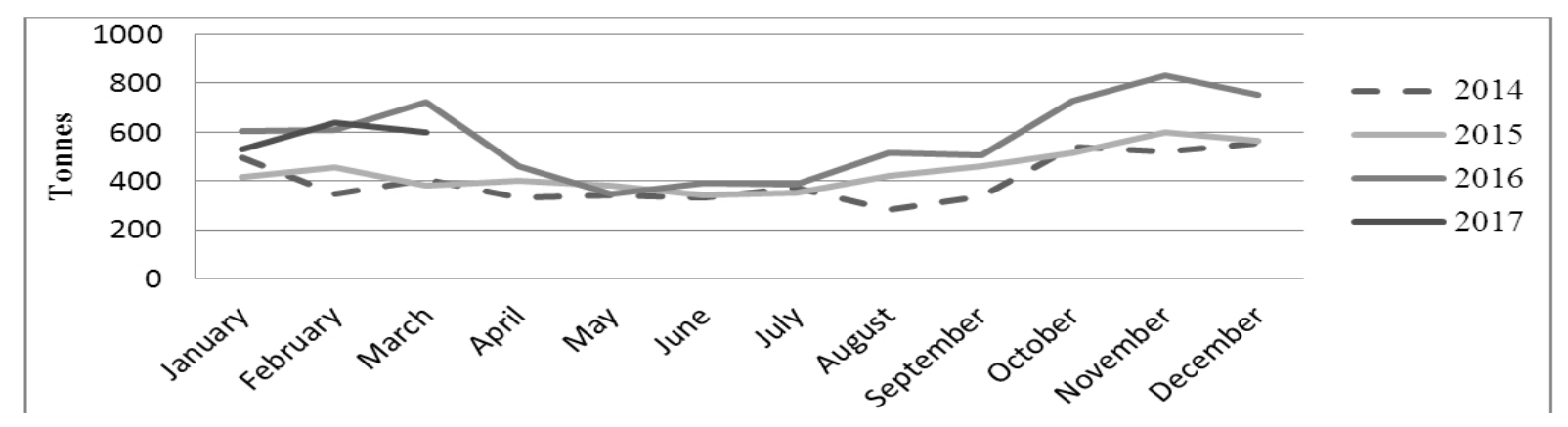

Figure 8. Monthly bovine meat produced at slaughterhouses

Source: Ministry of agriculture, food and forestry, Department "Agrostatistcs"

As a small producer, Bulgaria is under severe pressure from imported meat products. At present, there is an additional factor of the trends in the import and export of beef in Bulgaria, the imposed embargo by Russia on imports of agriproducts from the EU because much of the production of $\mathrm{EU}$ countries destined for Russia enters Bulgaria.

In Bulgaria, imports of "Meat of bovine animals, fresh or chilled and frozen" for the period 2007-2012 followed a downward trend. After that by 2013 there is a rise in imports quantities (13). About 11 thousand tons are average imported in the country. The meat of the bovine animals is essentially frozen. In 2016 the imported meat is above average 13.5 thousand tons, which is $27.4 \%$ more than the previous year. This may be due to the increase of beef production in the EU at 2016.

The export of bovine meat from Bulgaria follows a similar downward trend in the first few years from 2007 to 2010 and has been steadily rising since then. From 2010 to 2016 the quantities have grown nearly 8 times and for 2016 the export amounts to more than 4 thousand tons. Thus, the foreign trade balance of bovine meat for the period is negative, but it is decreasing.

Consumption of bovine meat in Bulgaria during the period 2010-2015 is with downward trend, but after 2013 it is rising sharply (Figure 9). In 2015 it is estimated at 28.7 thousand tons of carcass weight, which is $12 \%$ more than the minimum for a period in 2013.

An important indicator of the market situation in a country is the relative share of imported meat in national consumption. It can also present the level of self-sufficiency with meat of each type. Absolute import levels at beef follow consumption trends, but the proportion of imported meat to consumption is different. It is average about $1 / 3$ of domestic consumption, reaching its peak in 2014 $44.5 \%$ and the minimum is in $2012-24.3 \%$. 
TURLAKOVA T., et al.

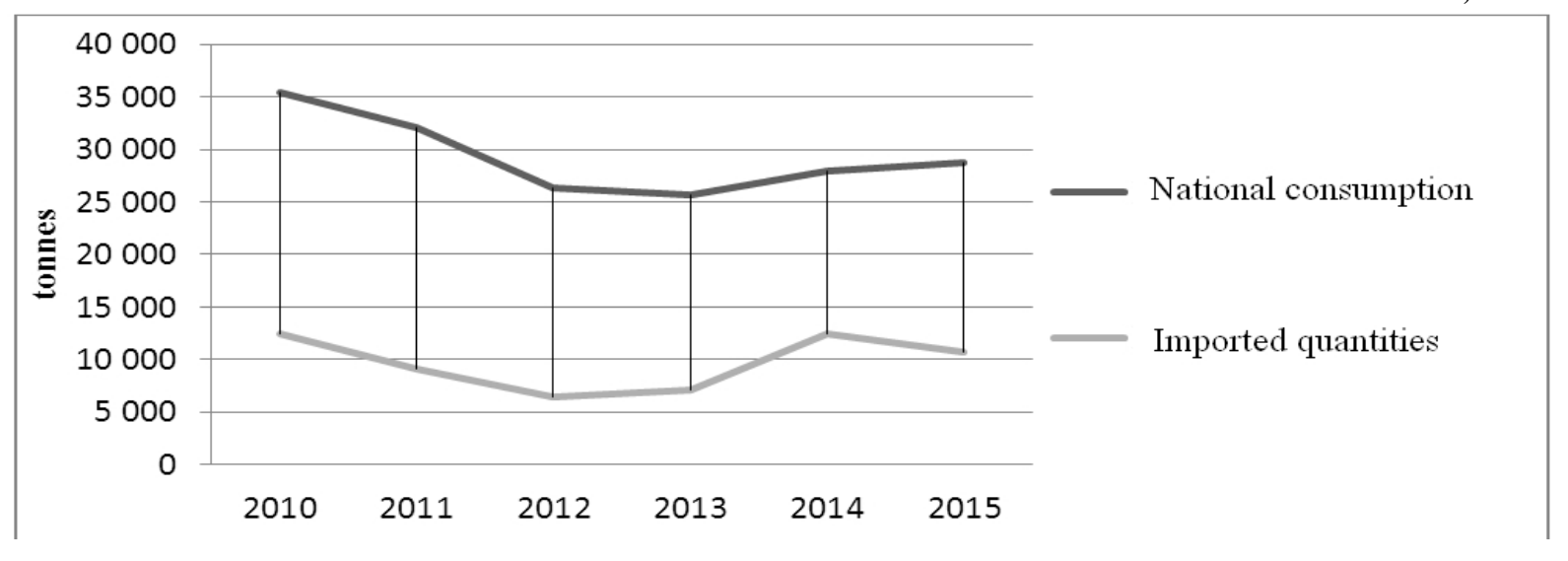

Figure 9. Domestic consumption and import of bovine meat

Source: Situational and prospective analysis of red meat for the period 2011-2015

Traditionally, the consumption of bovine meat in Bulgaria is in small quantities due to the low purchasing power of the population and the higher prices of this meat type than other meats such as pork and poultry. According to data of NSI, household consumption in recent years ranges around $1 \mathrm{~kg}$ per year, which does not include the quantities consumed in mass caterers. Compared to the EU levels $(10 \mathrm{~kg})$, it is clear that the consumption of beef in Bulgaria is very low and should be search opportunities for its raising because it has high nutritional and flavor qualities.

Prices of beef and veal on the Bulgarian market are influenced by the purchase prices of animals and international prices due to about $1 / 3$ of the consumed quantities are imported. According to data from INFOSAT to the NSI in the years of 2009 to 2014 there is a trend towards an increase in producer prices for young cattle from 1 to 2 years. From 2015 start decreasing, leading to some of the lowest values for the entire period (Figure 10). Despite the drop, the average price for 2016 2235 BGN per ton live weight is above the levels of 2009 and 2010, but compared to 2014 the decrease is about 500BGN/ton. For calves

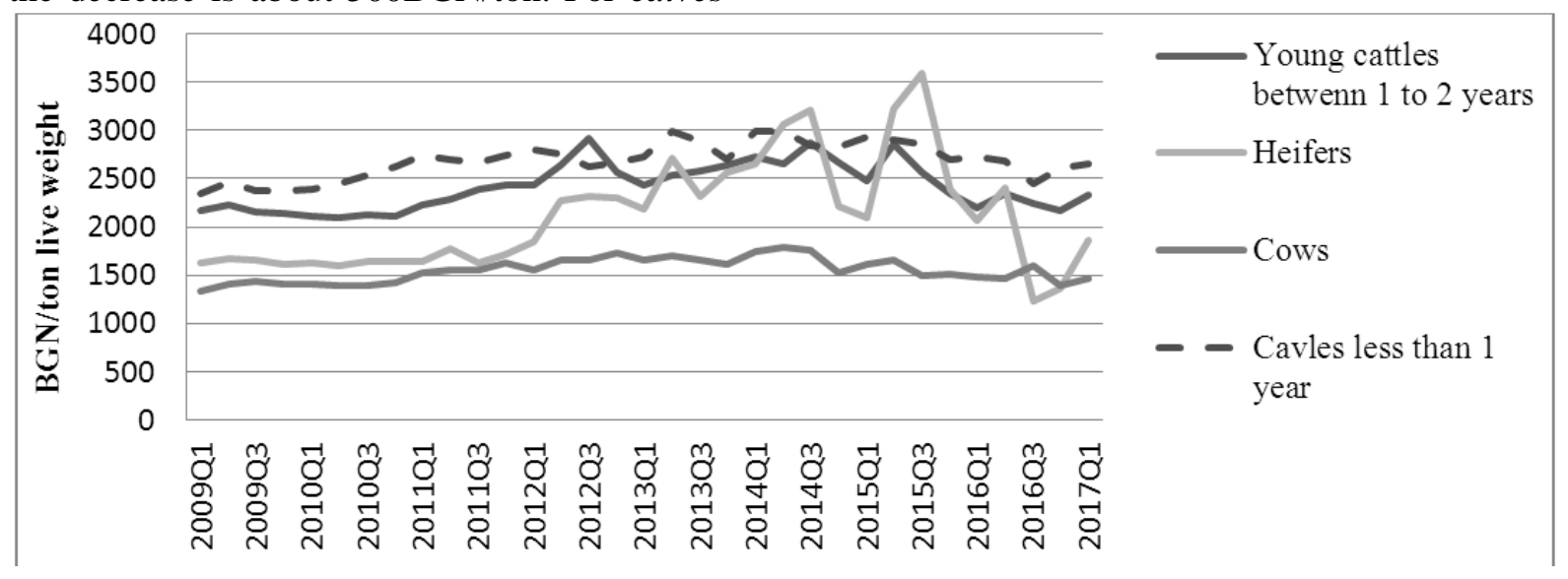

up to one year, there is also a rise up to 2014, after which the drop in purchase prices began steadily. For 2016 they were sole on average 2 $611 \mathrm{BGN} /$ ton live weight, which is by 300 BGN less compared to 2014. Duo to heifers, the situation is identical but there is a difference in 2015 when is reported a serious jump. This may be due to an increased demand for breeding animals during this period. After 2015 , prices collapse to their lowest levels since 2009. In cows there are no significant deviations in the purchase prices for the analyzed period, ranging between 1,400 and 1,700 BGN per ton. When comparing the Bulgarian data with the European market trends, the dynamics of prices based on live weight do not differ significantly. The deferens is only at the price increase until the end of 2013, followed by a decline in the next 3 years. This proves the dependence of the tendencies in the Bulgarian purchase prices from the EU level. In nominal terms, the prices paid in Bulgaria are significantly behind the average at EU-28. At 2016 they are lower by 837 BGN/ton for young cattle, by 1461 BGN for heifers and by 912 BGN for cows.

Figure 10. Selling prices of cattle at Bulgaria Source: www.infostat.nsi.bg 
Government support for meat cattle breeding

in Bulgaria aims to reduce the disproportion between the purchase price and the costs for it. According to the Ministry of agriculture analyzes, over the period 2011-2013 the prices for kilogram live weight is average 2,84BGN and the production costs are $3,38 \mathrm{BGN} / \mathrm{kg}$, which is the condition for the need of subsidizing. Other reason is the differences at international prices.

The first time by the schemes for meat cattle within CAP was applied at 2015. For meat cows and/or heifers more than 98,000 animals have been identified and for each were paid 252 BGN. In 2016, more than 122,000 animals have been claimed, and the support rate was 206 BGN.

The trend in campaigns 2015 and 2016 shows growing interest and increasing cattle which are claimed for support. The number of animals claimed for support under the selection control scheme for dairy and beef cattle was also significantly increased at 2016 by $35 \%$ (14).

From 2017 there have been changes in the support for meat breading cattle. The scheme for meat cows and/or heifers will funding up to 250 animals per farm and the budget will be reduced by $25 \%$ to 18,750 thousand $\mathrm{BGN}$, which will significantly reduce the rate for an animal. According to analyzes, it will fall to about 150 BGN per animal (15). Another change is also being prepared for a Dairy and/or Meat cattle under selection control scheme, which will be divided into both directions. For meat cows, under the selection control, the minimum is up to 20 cows per breed and introduced a modular rate for to 250th animal and over 250th. Here the planned budget is 3250 thousand $\mathrm{BGN}$ and the indicative rate is $210-260 \mathrm{BGN}$ per animal. A new way of support also requires proof of newborn calves (16).

The changes introduced in a policy on the support of meat-breeding cattle in Bulgaria show a focus on specialized breed animals grown for the purpose of obtaining better quality meat and higher production results rather than the development of meat-based cattle breeding based on dairy cows. This will also greatly change the market situation, and it is expected that the purchase prices of live weight to increase and determining according to the carcass weight and the carcass quality.

\section{CONCLUSION}

From analyze at the study can been made several conclusions:
TURLAKOVA T., et al.

- Worldwide the link between the number of bovine animals and the quantities of produced meat is not directly proportional.

- There were increasing in international beef prices in nominal and real terms over the past ten years, but in the next few years is expected a decline.

- It can't be drawn conclusive conclusion on the correlation between the number of bovines raised and the produced meat from them.

- At EU-28 the positive trend of the average meat productivity of cattle explains the inconsistencies in the proportions between the numbers of bred and processed cattle and the harvested meat

- The natural volumes of EU beef trade show a positive change in the EU's external trade balance for quantities of beef. At beef's external trade balance at values there is negative rising.

- Slaughterhouses average prices per 100 $\mathrm{kg} / \mathrm{carcass}$ weight (cwe) of all animal categories have tended to decline in recent years at EU.

- Meat cows in Bulgaria rising their proportion and the end of 2016 they formed $24 \%$ of all cows.

- Realized cattle and produced bovine meat decreased over past 10 years in Bulgaria.

- During the analyzed period (2007-2015) the meat productivity of cattle in Bulgaria decreased. The average productivity for all categories is so lower - $135 \mathrm{~kg}$ than in the EU (294 kg in 2015).

- In Bulgaria the ratio of harvested meat at farms is much more than at registered slaughterhouses (71 to $29 \%$ for 2015).

- There is seasonal yield of meat from bovine animals in Bulgaria. It increases during the autumn-winter period.

- The foreign trade balance of bovine meat for the period is negative, but it is decreasing.

- The share of imported meat in national consumption is average $1 / 3$ of domestic consumption.

- Consumption of bovine meat in Bulgaria after 2013 is rising sharply.

- From 2015 start decreasing, leading to some of the lowest purchase prices for the entire period.

- The prices paid in Bulgaria are significantly behind the average at EU-28.

- Changes in a policy in Bulgaria show a focus on specialized breed animals grown.

\section{REFERENCES}

1. FAO. FAO Statistical Pocketbook. Rome: FAO, 2015. 
2. FAOSTAT.http://www.fao.org/faostat/en/\# data. [Online]

3. USDA, Department "Foreign Agricultural Service". World Agricultural Outlook Board. 2017.

4. OECD/FAO. OECD-FAO Agricultural Outlook 2016-2025. Paris : OECD Publishing, 2016.

5. OECD. OECD Agriculture statistics (database).

http://dx.doi.org/10.1787/888933381890. [Online] 2017.

6. EUROSTAT.http://ec.europa.eu/eurostat/da ta/database. [Online] 2017.

7. CMO Committee, EC - Agriculture and Rural Development. BEEF \& VEAL MARKET SITUATION. 2017.

8. European Commission, Directorate-General for Agriculture and Rural Developmnet. EU trade in quantities by commodity, import/export/balance.

9. European Commission, Directorate-General for Agriculture and Rural Development. AGRI-FOOD TRADE STATISTICAL
TURLAKOVA T., et al. FACTSHEET, European Union - Extra EU 28. 2017.

10.European Commission, Directorate-General for Agriculture and Rural Developmnet. Meat Market Observatory. 2017.

11.Ministry of agriculture, food and forestry, Department "Agrostatistcs". Livestock at Bulgaria by November 2016. Sofia: s.n., 2017.

12.The activity of slaughterhouses for red meat and meat production in Bulgaria in 20072015. Sofia : s.n., 2016.

13.NSI. http://ftrade.nsi.bg/. [Online] 2017.

14.Ministry of agriculture and food, Directorate "Direct Payments and Quality Schemes". Voluntary coupled support 2015-2016. Sofia : s.n., 2016.

15.http://www.mzh.government.bg/. Voluntary coupled support (2017-2020). [Online] 2016.

16.APPLICATION HANDBOOK DIRECT PAYMENTS CAMPAIGN 2017. [Online] 2017. 